\title{
Experimental evidence for previously unclassified calcium phosphate structures in the casein micelle
}

\author{
J. P. Hindmarsh ${ }^{* 1}$ and P. Watkinson $†$ \\ *Massey Institute of Food Science and Technology, Massey University, Riddet Road, Palmerston North, New Zealand 4474 \\ †Fonterra Research and Development Centre (FRDC), Fitzherbert Dairy Farm Road, Palmerston North, New Zealand 4442
}

\begin{abstract}
${ }^{1} \mathrm{H}_{-}{ }^{31} \mathrm{P}$ Cross-polarization magic angle spinning (CPMAS) measurements of 40-d-old Mozzarella cheese and $20 \mathrm{~m} M$ EDTA-treated casein micelles revealed that each sample had immobile phosphorus with the same spectral pattern, which did not match that of native casein micelles. To identify the immobile phosphorus bodies, ${ }^{1} \mathrm{H}-{ }^{31} \mathrm{P}$ CP-MAS spectra and cross-polarization kinetics measurements were undertaken on native casein micelles, EDTA-chelated casein micelles, and reference samples of $\beta$-casein and hydroxyapatite. The results showed that the immobile phosphorus bodies in the mature Mozzarella cheese had the following characteristics: they are immobile phosphoserine residues (not colloidal calcium phosphate); they are not the product of phosphoserine to colloidal calcium phosphate bridging; the phosphate is complexed to calcium; their rigidity is localized to a phosphorus site; their rigidity and bond coupling is unaffected by protein hydration; and the immobile bodies share a narrow range of bond orientations. Combining these observations, the best explanation of the immobile phosphorus bodies is that bonding structures of phosphorus-containing groups and calcium exist within the casein micelle that are not yet clearly classified in the literature. The best candidate is a calcium-bridged phosphoserine-to-phosphoserine linkage, either intra- or inter-protein.
\end{abstract}

Key words: ${ }^{1} \mathrm{H}_{-}{ }^{31} \mathrm{P}$ cross-polarization magic angle spinning (CP-MAS), casein micelle, calcium phosphate

\section{INTRODUCTION}

At first glance, casein micelles are nano-sized spherical assemblages $(80-400 \mathrm{~nm})$ of casein proteins $\left(\alpha_{\mathrm{S} 1}, \alpha_{\mathrm{S} 2}\right.$, $\beta$, and $\kappa$ ) and minerals $(\mathrm{Ca}, \mathrm{P}, \mathrm{Mg}$ ) in milk. Yet they have the characteristics of complex biological machines. They can exchange proteins and minerals, transport

Received January 20, 2017.

Accepted May 17, 2017.

${ }^{1}$ Corresponding author: j.p.hindmarsh@massey.ac.nz minerals $(\mathrm{Ca}$ and $\mathrm{P})$ in solution at supersaturated concentrations, absorb approximately 6 times their weight in water, and dissemble and reassemble their structure in different chemical environments (Horne, 2011). Casein micelles contain phosphorus in 2 chemical forms: calcium phosphate deposits and phosphorylated serine (phosphoserine) in the caseins (Thomsen et al., 1995; Bak et al., 2001). The calcium phosphate deposits are also described as colloidal calcium phosphate (CCP) nanoclusters (Horne, 1998). One currently accepted view is that casein micelles are assembled by interprotein bonding by van der Waals forces, hydrophobic bonds, and ionic calcium linkages around the CCP nanoclusters (Horne, 1998, 2011; Phadungath, 2005; Dalgleish, 2011). The calcium bridged CCP to phosphoserine linkage is illustrated in Figure 1.

The CCP is an immobile (rigid) amorphous inorganic salt (Horne, 1998). Thomsen et al. (1995) showed that phosphorus $\left({ }^{31} \mathrm{P}\right)$ solid-state nuclear magnetic resonance (NMR) could differentiate between the mobile and immobile phases of the phosphorus species in casein micelles. They used the NMR technique of protonto-phosphorus $\left({ }^{1} \mathrm{H}_{-}{ }^{31} \mathrm{P}\right)$ cross-polarization magic angle spinning (CP-MAS; Thomsen et al., 1995). They showed a major fraction of the phosphoserine residues in the casein micelle proteins were immobilized due to their cross-linking with rigid CCP clusters by caseinate calcium (calcium that links phosphoserine to the CCP). The CP-MAS technique involves polarization transfer from an abundant nucleus $\left({ }^{1} \mathrm{H}\right)$ to a dilute nucleus $\left({ }^{31} \mathrm{P}\right)$. The CP-MAS experiment acts as a filter for detecting only the immobile component (rigid species) in a heterogeneous sample. It does this because crosspolarization (CP) relies on a strong static component of the dipolar interaction between the proton and the other nucleus. This implies that if the molecule can reorientate in space more than once during the $\mathrm{CP}$ period (typically $1 \mathrm{~ms}$ ), then the net magnetization transfer will be zero. Hence, CP-MAS is efficient for detecting immobile, rigid molecular species but ineffective for mobile, fluid-like species (Kolodziejski and Klinowski, 2002). 


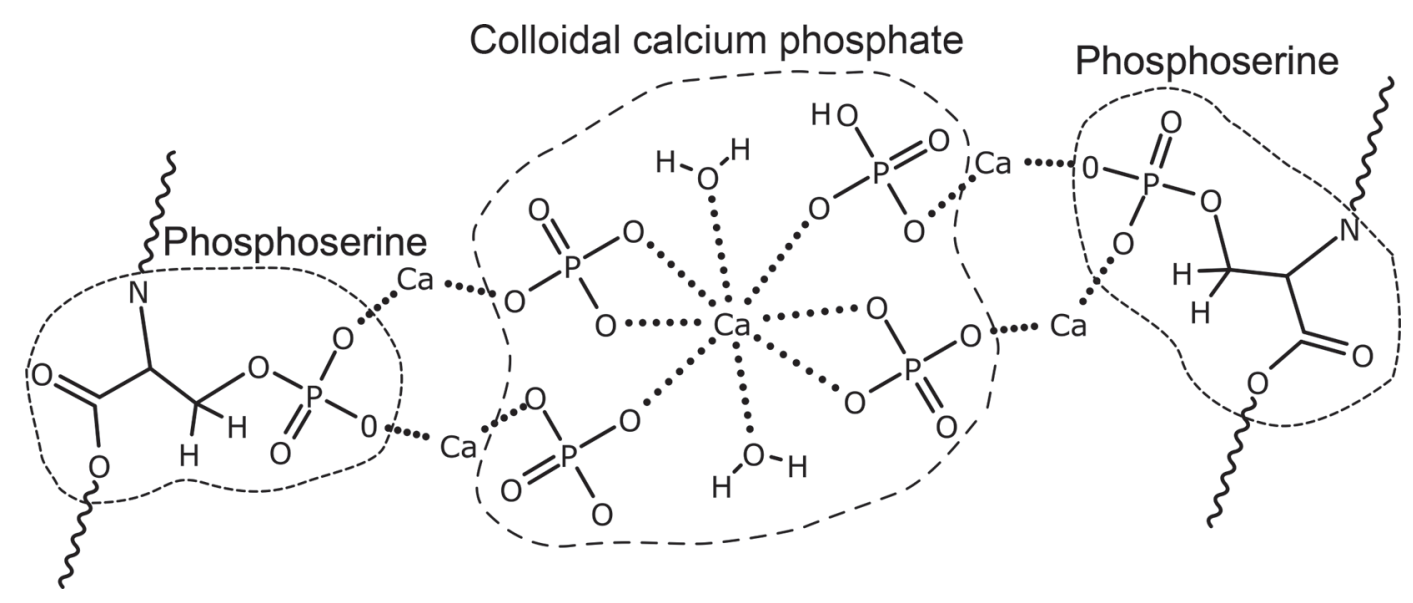

Figure 1. Representative structure of casein micelle inter-protein linkages by calcium-bridged phosphoserine to colloidal calcium phosphate. Structure derived from colloidal calcium phosphate structure proposed by Holt et al. (1989) and cross-linkage structure by Horne et al. (1998).

Gobet et al. (2010) applied the ${ }^{1} \mathrm{H}^{31} \mathrm{P}$ CP-MAS method to cheese. Their goal was to observe the state and distribution of immobile/mobile phosphorus species for different cheeses. Their results showed that mature cheese contained significant amounts of rigid CCP and phosphoserine phosphorus. This was an interesting discovery because the casein proteins in cheese are in a hydrated state but the phosphoserine residues were still held in an immobile state by their linkages to the CCP.

We applied ${ }^{1} \mathrm{H}^{31} \mathrm{P}$ CP-MAS to monitor the state of the phosphorus in maturing Mozzarella cheese during storage. Figure 2 shows the ${ }^{1} \mathrm{H}^{31} \mathrm{P}$ CP-MAS spectra of a Mozzarella sample over $40 \mathrm{~d}$. Five peaks can be observed in each spectra; the center peak is the isotropic peak. Spanning either side of the isotropic peak are the first- and second-order spinning sideband peaks. The isotropic peak is the product of the isotropic chemical shift of the ${ }^{31} \mathrm{P}$ nuclei of the $\mathrm{CCP}$ and the phosphoserine. Due to peak broadening, the CCP and phosphoserine appear as one isotropic peak. Sideband peaks are offset from the isotropic peak in intervals of the spinning frequency of the MAS rotor (Wu et al., 1994; Gobet et al., 2010). The amplitude of the sideband peaks approximates the powder pattern of the chemical shift anisotropy (CSA) of each ${ }^{31} \mathrm{P}$ site. The peak intensity of the cross-polarized isotropic peak is proportional to the concentration of rigid phosphorus in the Mozzarella cheese. The decline in isotropic peak area shows the rigid phosphorus content of the Mozzarella decreased during storage. It is widely reported that the micellar CCP is mobilized into cheese serum during cheese aging (Hassan et al., 2004; Guinee and O'Kennedy, 2009). It is noteworthy that the spinning side-band peaks did not decline at the same rate as the isotropic peak during the Mozzarella aging. This means the CSA pattern of the phosphorus changed with mobilization of micellar phosphate. This was repeatable for 3 Mozzarella samples.

The CSA pattern can act as a chemical "fingerprint," because it is the product of the chemical environment of the nuclei. The chemical environment depends on the type and proximity of other nuclei and the bonding characteristics (strength and geometry). Protons have the strongest influence on the CSA pattern of phosphorus (strong coupling). Thus, protons produce high intensity spinning side bands (Wu et al., 1994). The chemical structure of CCP has yet to be defined but

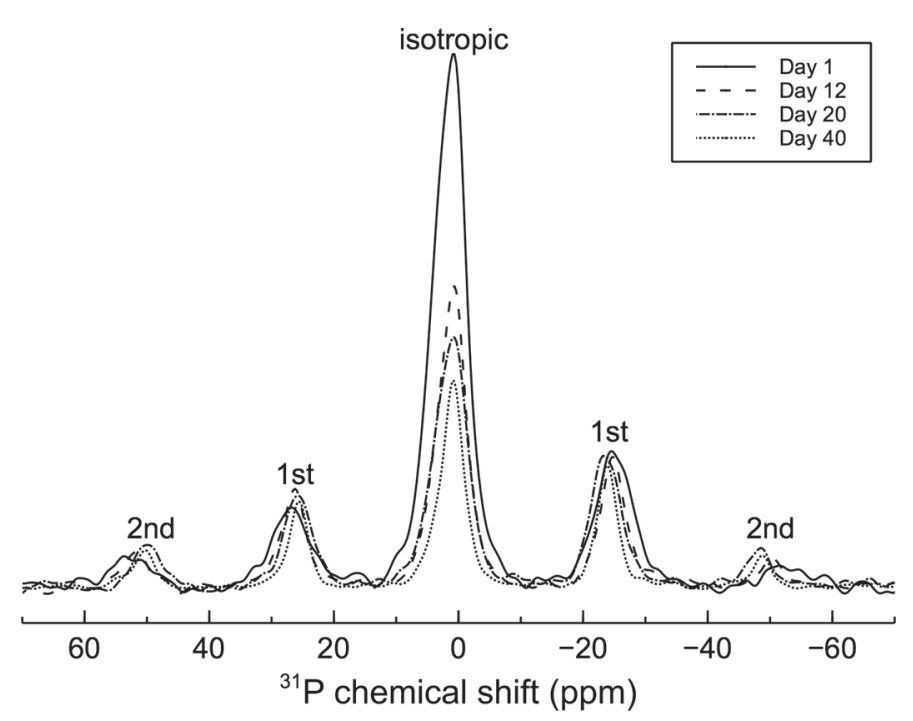

Figure 2. ${ }^{1} \mathrm{H}-{ }^{31} \mathrm{P}$ Cross-polarization magic angle spinning (CPMAS) spectra of Mozzarella cheese stored at $4^{\circ} \mathrm{C}$ over $40 \mathrm{~d}$. Spinning side bands are indicated by their order number (first, second) from the central isotropic peak of the phosphorus signal. 
several researchers have identified amorphous hydroxyapatite [HAP; $\left.\mathrm{Ca}_{10}(\mathrm{OH})_{2}\left(\mathrm{PO}_{4}\right)_{6}\right]$ as a good candidate (Sleigh et al., 1983; Rasmussen et al., 1997; Bak et al., 2001; Holt, 2004; Gaucheron, 2005). Wu et al. (1994) presented ${ }^{1} \mathrm{H}^{31} \mathrm{P}$ CP-MAS spectra of amorphous HAP and freeze-dried $\beta$-casein (immobile); reproduced spectra are shown in Figure 3. $\beta$-Casein and amorphous HAP have characteristically different CSA patterns because the phosphorus nucleus in phosphoserine is near covalently bonded protons (see Figure 1), whereas the closest protons to the HAP phosphorus nuclei are ionically bound water (weakly coupled).

We would expect that the phosphoserine involved in cross-linking with CCP would be mobilized as CCP decreases during cheese aging. If the immobile phosphoserine content decreases with the $\mathrm{CCP}$, the intensity of all spinning side bands would be expected to reduce at a similar rate to the isotropic peak. But this was not observed. The purpose of this investigation was to identify the makeup of the immobile phosphorus present in the casein micelles if the CCP has been mobilized.

Solid-state NMR methods were used to identify the immobile phosphorus species present in casein micelles after CCP depletion. The immobile phosphorus species can be identified by their ${ }^{31} \mathrm{P}$ NMR CSA pattern and by their respective ${ }^{1} \mathrm{H}_{-}{ }^{31} \mathrm{P}$ CP kinetics (rate of magnetization transfer between ${ }^{1} \mathrm{H}$ and ${ }^{31} \mathrm{P}$ nuclei). The ${ }^{1} \mathrm{H}_{-}{ }^{31} \mathrm{P}$ CP kinetics of the phosphoserine and CCP are known to be different (Wu et al., 2003). Cross-polarization kinetics depend on several factors: population of source nuclei $\left({ }^{1} \mathrm{H}\right)$, the spatial separation between the source nuclei and target nuclei $\left({ }^{31} \mathrm{P}\right)$, the chemical bonding (dipolar interactions), and the molecular mobility of the source and target (Kolodziejski and Klinowski, 2002). The ${ }^{1} \mathrm{H}_{-}{ }^{31} \mathrm{P}$ CP kinetics are faster in phosphoserine than in CCP. The phosphorus nuclei in the phosphoserine residues have 2 covalently bonded protons (strong dipolar coupling) near the phosphate nuclei (see Figure 1a), whereas in the CCP, the closest protons are more distant and are from ionically bonded water (weak dipolar interactions; Figure 1). Cross-polarization kinetics can be measured with the TORQUE (T One Rho QUEnching) method (Kolodziejski and Klinowski, 2002). Identification is also aided by ${ }^{1} \mathrm{H}-{ }^{31} \mathrm{P}$ spectra and $\mathrm{CP}$ kinetics of reference components of the phosphorus-containing sections of the casein micelles, these being the phosphoserine and CCP. The $\alpha_{\mathrm{S}^{-}}, \alpha_{\mathrm{S}^{-}}$, $\beta$-, and $\kappa-\mathrm{CN}$ all contain phosphorylated sites but $\beta-\mathrm{CN}$ and calcium- $\beta-C N$ were used to produce reference ${ }^{31} \mathrm{P}$ spectra for the phosphoserine (Bingham, 1979).

Chelation of the calcium with EDTA can deplete the CCP in casein micelles in a controlled manner (Marchin et al., 2007). Micro-filtration was used to isolate the
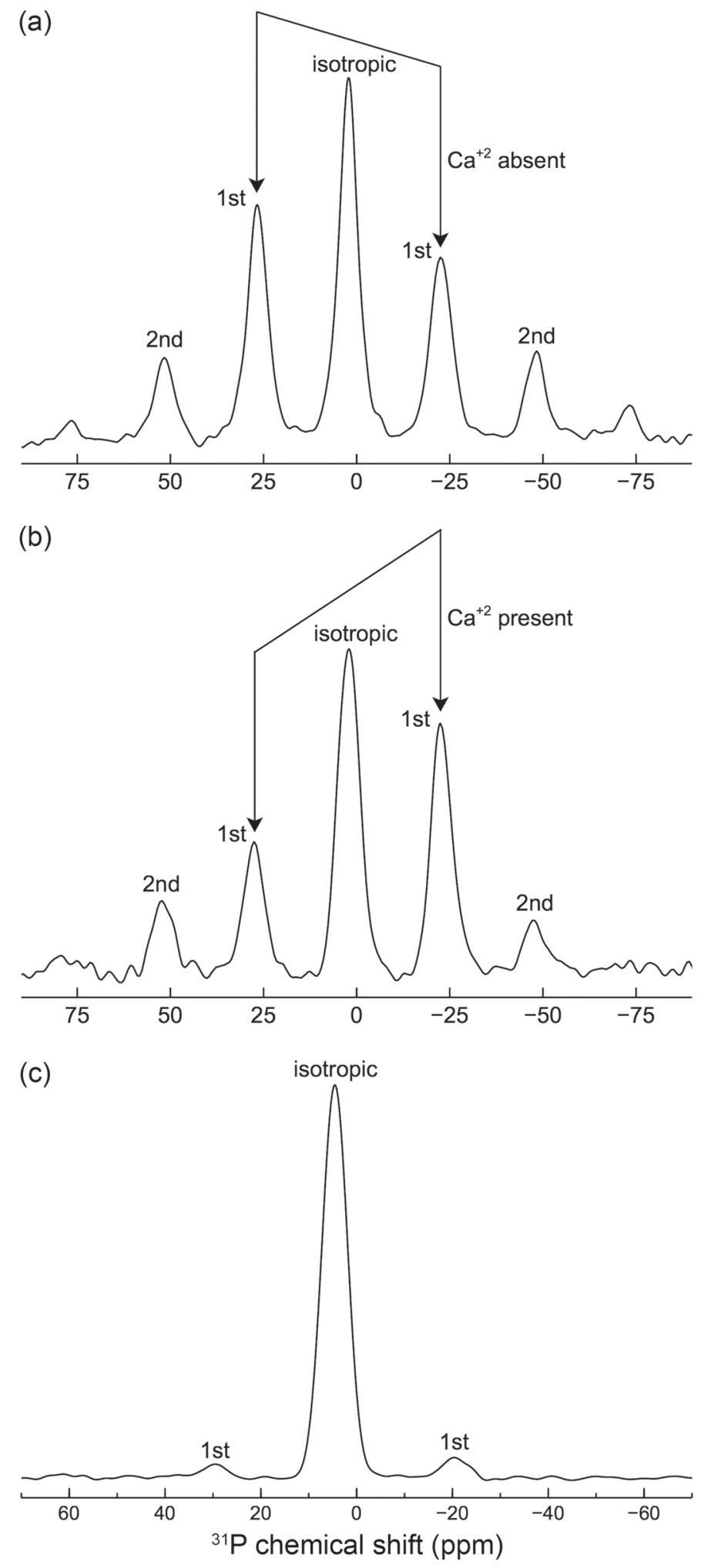

Figure 3. ${ }^{1} \mathrm{H}_{-}{ }^{31} \mathrm{P}$ Cross-polarization magic angle spinning (CPMAS) spectra of (a) dry $\beta$-casein, (b) calcium- $\beta$-casein complex, and (c) hydroxyapatite (HAP). These are experimentally reproduced data of Wu et al. (1994). 
casein micelles from skim milk (Kelly et al., 2000). The isolated casein micelles were then treated with different concentrations of EDTA, and then concentrated into a wet pellet with ultracentrifugation. The pellets were then analyzed with solid-state NMR.

\section{MATERIALS AND METHODS}

\section{Casein Micelle Pellet Formation}

Raw milk (Massey University Dairy Unit 1, Palmerston North, New Zealand) was skimmed with a centrifugal clarifier at $42^{\circ} \mathrm{C}$. Milk permeate was generated from a portion of the skim milk by ultrafiltration with a 0.6-kDa membrane (GE Infrastructure, Newark, DE). Casein micelles were concentrated from 200-mL volumes of skimmed raw milk by micro-filtration with a 0.1- $\mu \mathrm{m}$ membrane (Merck Millipore, Billerica, MA; Kelly et al., 2000), and the retentate was recycled. When the retentate volume was reduced by half, fresh milk permeate was added to replace the lost volume. This was repeated until the original skim milk volume had been replaced 7 times (1,400 $\mathrm{mL}$ of milk permeate). This washing reduces the whey and lactose concentration to produce a concentrated casein micelle solution, albeit with some lactose still present. The protein composition was observed with SDS-PAGE. Changes in the SDS band intensity for the casein and whey showed the casein to whey ratio had been increased from 4:1 to $9: 1$. The measured content of the solid fraction was protein $65 \%$ (wt/wt, dry solids), lactose $34 \%$, and the remaining $1 \%$ ash and fat.

A casein micelle pellet was formed by ultracentrifugation at $50,000 \times g$ for $1 \mathrm{~h}$ at $20^{\circ} \mathrm{C}$ in 50 -mL tubes. Typical casein micelle separation is done at 100,000 $\times$ $g$ (Zhang and Aoki, 1996). At this higher gravity, the casein micelle pellet formed has layers of varying casein micelle sizes. In an effort to form a uniform pellet, the lower centrifugation speed of $50,000 \times g$ was used.

\section{Cheese Making}

A commercial 10-kg block of Mozzarella cheese was obtained immediately after a 24-h rapid cool cycle following manufacture (Fonterra Cooperative Group, Palmerston North, New Zealand). Composition of the cheese by weight was $49.7 \%$ water, $25.4 \%$ protein, $20.2 \%$ fat, $3.2 \%$ ash, and $1.5 \%$ lactose. The $10-\mathrm{kg}$ block was then cut into 20 equal-sized blocks, vacuum packed, and stored at $4^{\circ} \mathrm{C}$. The blocks were randomly selected on each day of the trial. Samples for NMR analysis were taken from the core of the blocks.

\section{Casein Micelle Chelation}

The chelation agent EDTA was used to produce casein micelle solutions of varying levels of calcium depletion. Solutions varying from 5 to $20 \mathrm{~m} M$ EDTA were prepared. A $250 \mathrm{~m} M$ EDTA stock solution was used. The $\mathrm{pH}$ of the EDTA solution was slowly increased to $\mathrm{pH} 6.8$ to fully dissolve the EDTA salt by the addition of $1 M \mathrm{NaOH}$. The EDTA solution was added drop-wise into 80 - to $100-\mathrm{mL}$ aliquots of casein micelle solution that was stirred using a magnetic stirrer. The chelated milk was left on the stirrer to equilibrate over $12 \mathrm{~h}(0.1 \%$ azide added to reduce microbiological spoilage). Following that, the $\mathrm{pH}$ was adjusted to 6.8 with 1 $M \mathrm{NaOH}$ solution.

\section{Reference Samples}

Hydroxyapatite $\left[\mathrm{Ca}_{10}(\mathrm{OH})_{2}\left(\mathrm{PO}_{4}\right)_{6}\right]$ was obtained from Sigma Aldrich (Sigma-Aldrich New Zealand Ltd., Auckland, New Zealand). $\beta$-Casein was sourced from Fonterra Research and Development Centre (Palmerston North, New Zealand). Calcium salts of $\beta-\mathrm{CN}$ were prepared as follows: $200 \mathrm{mg}$ of calcium-free $\beta-\mathrm{CN}$ was dissolved in $20 \mathrm{~mL}$ of ion-free water. At room temperature $\left(22^{\circ} \mathrm{C}\right)$, a degassed solution of $4 \mathrm{M} \mathrm{CaCl}_{2}$ was slowly added from a burette while stirring until precipitation of the protein was complete. The precipitate was centrifuged at $50,000 \times g$ for $45 \mathrm{~min}$; then, the pellet collected, washed 3 times with $10 \mathrm{~m} M$ Tris- $\mathrm{HCl}$ buffer at $\mathrm{pH} 8.5$ to remove excess $\mathrm{Ca}$, and lyophilized (Wu et al., 2003).

\section{NMR Methods}

All solid-state NMR spectra were acquired on a Bruker BioSpec spectrometer (Elektronik GmbH, Rheinstetten, Germany) operating at a ${ }^{1} \mathrm{H}$ frequency of $200.32 \mathrm{MHz}$ and $\mathrm{a}^{31} \mathrm{P}$ frequency of $81.09 \mathrm{MHz}$. The experiments were conducted with a Bruker 7-mm double resonance $\mathrm{H} / \mathrm{X}$ SB-MAS (magic angle spinning) probe at a regulated temperature of $22^{\circ} \mathrm{C}$. Typically, $150 \mathrm{mg}$ of sample (dry weight) was packed into a $7-\mathrm{mm}$ rotor with a watertight cap. The $90^{\circ}$ pulses for ${ }^{1} \mathrm{H}$ and ${ }^{31} \mathrm{P}$ were both set to $5.54 \mu \mathrm{s}$. During all acquisitions, a $45-\mathrm{kHz}$ dipolar proton decoupling was used. The rotor spinning speed was maintained at 2,000 $\pm 10 \mathrm{~Hz}$. All ${ }^{31} \mathrm{P}$ chemical shifts were referenced externally to $85 \% \mathrm{H}_{3} \mathrm{PO}_{4}$. All spectra were zero filled to 4,096 data points and processed with a $10-$ to $70-\mathrm{Hz}$ Lorentzian line broadening and a 0.010-s Gaussian broadening. For each sample, spectra were acquired with CP-MAS and 
TORQUE acquisition sequences. Details of the acquisition of each spectra are provided below.

\section{Cross-Polarized Spectra}

A single contact pulse $\mathrm{CP}$ sequence was used. The Hartmann-Hahn contact time was $2.3 \mathrm{~ms}$. The flame ionization detection acquisition time was $15 \mathrm{~ms}$ with 959 data points. A 2-s recycle delay was used to minimize radio frequency heating by maintaining the highpower decoupling duty cycle below $1 \%$.

\section{CP Kinetics}

The TORQUE sequence was used to measure the proton to phosphorus $\left({ }^{1} \mathrm{H}\right.$ to $\left.{ }^{31} \mathrm{P}\right) \mathrm{CP}$ kinetics. Details of the pulse sequence are given by Kolodziejski and Klinowski (2002). In the experiment, the overall spinlock time is kept constant (sum of spin-lock and contact time) and the contact time ( $\mathrm{CP}$ time) is varied. This eliminates the signal changes due to spin-lattice relaxation in the rotating frame. A total spin-lock time of 4 ms was used. Fourteen contact times ranging from 0.1 to $3.5 \mathrm{~ms}$ were used. Field induction decay was acquired with a sweep width of $40 \mathrm{kHz} ; 1,216$ data points were collected over an acquisition time of $15 \mathrm{~ms}$.

\section{RESULTS AND DISCUSSION}

Figure 4a shows the ${ }^{1} \mathrm{H}^{31} \mathrm{P}$ CP-MAS spectra of a Mozzarella cheese sample after $1 \mathrm{~d}$ of storage at $4^{\circ} \mathrm{C}$ and a pellet of native casein micelle (wet). The spectra are almost identical, the only notable difference being the height of the right first-order spinning side band. $\mathrm{Wu}$ et al. (2003) observed that calcium complexing to the phosphate ion changed the relative amplitude of the left and right first-order spinning side bands for phosphoserine and calcium phosphate salts (e.g., HAP, brushite; see Figure $3 \mathrm{a}$ and $\mathrm{b}$ ). The concentration of calcium changes the magnitude of the slope between the first-order spinning side-band peaks. The casein micelle pellet should contain almost fully intact CCP. Therefore, the ${ }^{1} \mathrm{H}-{ }^{31} \mathrm{P}$ CP-MAS spectra indicate that the Mozzarella making process only slightly reduced the level of calcium complexed to the immobile phosphorus in the casein micelles. This is consistent with reports that during cheese manufacture, the calcium to phosphate ratio tends to decrease as the overall mineral content of cheese decreases (Lucey and Fox, 1993).

After $40 \mathrm{~d}$ of storage, the ${ }^{1} \mathrm{H}-{ }^{31} \mathrm{P}$ CP-MAS spectrum of the Mozzarella did not match that of the native casein micelles but was similar to that of calcium-precipitated $\beta$-CN (Figure 4b). The CSA (chemical environment) of the rigid phosphorus remaining in the Mozzarella cheese was that of calcium- $\beta-\mathrm{CN}$ with a reduced concentration of calcium complexing with phosphate ion, as indicated by the lower intensity of the left side firstorder spinning side band. The only phosphorus species in calcium- $\beta-\mathrm{CN}$ are phosphoserine residues. These are in an immobile state due to the protein being dry. The ${ }^{1} \mathrm{H}-{ }^{31} \mathrm{P}$ CP-MAS spectra of the hydrated calcium- $\beta-\mathrm{CN}$ (formed by calcium-induced precipitation) showed only trace amounts of rigid phosphorus. This could be from incompletely hydrated casein particles. This indicates that calcium complexing to the phosphoserine on the $\beta-\mathrm{CN}$ did not maintain rigidity in the phosphate site when it was hydrated. Therefore, the rigid phospho-

(a)

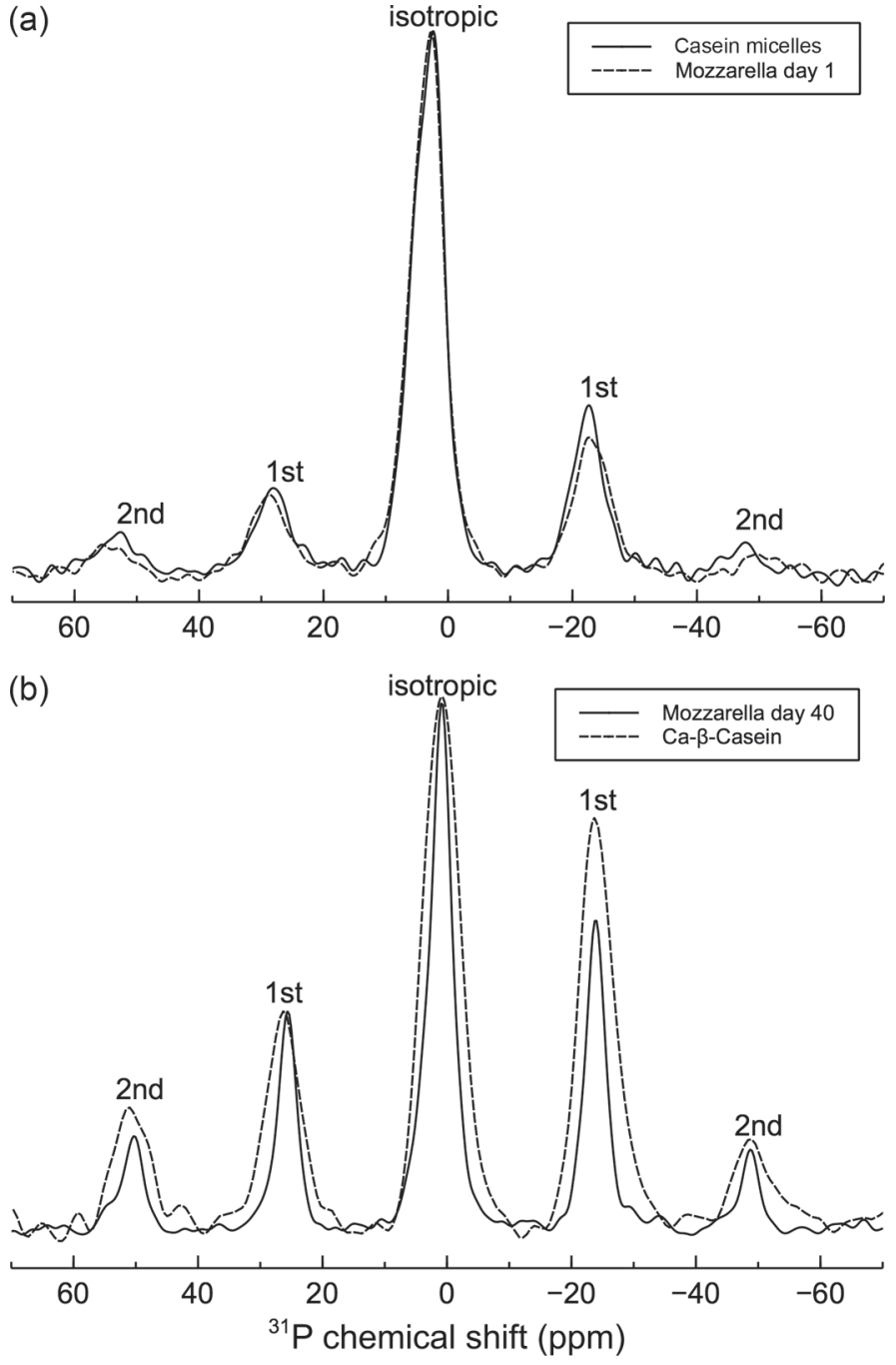

Figure 4. Comparison of ${ }^{1} \mathrm{H}^{31} \mathrm{P}$ cross-polarization magic angle spinning (CP-MAS) spectra of (a) Mozzarella after $1 \mathrm{~d}$ against native casein micelle pellet; (b) Mozzarella after $40 \mathrm{~d}$ against dry calcium- $\beta$ casein. Spectra were normalized to the height of largest peak. 
rus observed in 40-d-old Mozzarella is phosphoserine complexed to calcium. Also, precipitation of $\beta-\mathrm{CN}$ with calcium does not appear to form rigid phosphoserine bodies. This suggests the rigid phosphoserine observed in the casein micelles is characteristic of the casein micelle structure.

The ${ }^{1} \mathrm{H}_{-}{ }^{31} \mathrm{P}$ CP kinetics (rate of magnetization transfers from the proton to phosphorus nuclei) can be used to confirm the observations from the ${ }^{1} \mathrm{H}^{31} \mathrm{P}$ CP-MAS spectra. It is predicted that casein micelles will contain $2{ }^{1} \mathrm{H}^{31} \mathrm{P}$ CP kinetics: a fast transfer occurring within the phosphoserine and a much slower transfer within the CCP. The ${ }^{1} \mathrm{H}^{31} \mathrm{P}$ CP kinetics of a pellet of native casein micelles, HAP, and calcium- $\beta-\mathrm{CN}$ are shown in Figure 5. Plotted are the normalized peak integral (peak integral divided by total signal of all time points) versus the $\mathrm{CP}$ time. The ${ }^{1} \mathrm{H}_{-}{ }^{31} \mathrm{P} \mathrm{CP}$ kinetic curve of the casein micelle pellet has heterogeneous characteristics ( $2 \mathrm{CP}$ rates). The best fit was with a 2 -site $\mathrm{CP}$ rate equation (Kolodziejski and Klinowski, 2002):

$$
I_{t}=I_{0}-I_{1} \exp \left(-\frac{t}{\tau_{P s e r}}\right)-I_{2} \exp \left(-\frac{t}{\tau_{C C P}}\right) \times 0.1,
$$

where $I_{t}$ is the total transferred magnetization; $\tau_{\text {Pser }}$ and $\tau_{C C P}$ are the $\mathrm{CP}$ rate constants of phosphoserine and CCP, respectively; $I_{1}$ and $I_{2}$ are the equilibrium magnetization intensity of the respective nuclei and are proportional to the population of signal donors and the efficiency of magnetization transfer; and $I_{0}$ is the total potential equilibrium magnetization transfer. A curve fitting Eqn. [1] to the casein micelle CP kinetic curve in Figure 5 indicated that the $\mathrm{CP}$ rate constants in phosphoserine and CCP were 0.21 and $3.1 \mathrm{~ms}$, respectively. From the fit, the individual CP kinetic curves of the phosphoserine and the CCP could be plotted in Figure 5 . They showed good approximation to the measured kinetics of calcium- $\beta-\mathrm{CN}$ and HAP, respectively, supporting the speculation that the CCP in casein micelles is HAP. The calcium- $\beta-\mathrm{CN}$ is dry, whereas the casein micelles pellets are hydrated but there is minimal difference between the CP kinetics of the respective phosphoserine residues. This supports the observation that the casein micelle phosphoserine residues are held in an immobile/rigid state, even though the casein micelle is in a hydrated state.

Proton-to-carbon cross-polarized $\left({ }^{1} \mathrm{H}_{-}{ }^{13} \mathrm{C}\right.$ CP-MAS $)$ spectra of the hydrated casein micelle pellets showed no detectable peaks (spectra only show flat noise). The mobility of the carbons was too high for efficient CP to occur. This indicates that the immobilization of the phosphoserine residues in a hydrated casein micelle is highly localized to the serine phosphate site (see Figure $1)$.

The ${ }^{31} \mathrm{P}$ CP-MAS spectra of the native casein micelle pellet (Figure 4a) is a mixture of CCP and phosphoserine residues. Using the cross-polarization model in Eqn. [1], it is possible to extract the individual sub-spectra. At a $0.1 \mathrm{~ms}$ CP time for the native casein micelle pellet, it is predicted the phosphoserine residues will be $95 \%$ of the signal. Thus, the $0.1 \mathrm{~ms}$ CP time spectra is a good representation of the CP-MAS spectrum of the rigid phosphoserine residues in casein micelles. This spectrum is shown in Figure 6a. Also plotted in Figure $6 \mathrm{a}$ is the CP-MAS spectrum of casein micelles at the longest $\mathrm{CP}$ time of $3.3 \mathrm{~ms}$. The spectrum in Figure $6 \mathrm{a}$ is predicted to contain the fully polarized phosphoserine and the CCP phosphorus at $65 \%$ polarization. In Figure $6 \mathrm{a}$, the phosphoserine spectrum has been rescaled to its predicted contribution of the overall spectra. A sub-spectrum of the probable CCP can be extracted by subtracting the 2 spectra in Figure 6a, with the result shown in Figure 6b. Also plotted in Figure 6b is the spectrum of HAP. The spectra are very similar. This confirms that the rigid phosphorus observed in 40-d-old Mozzarella is not CCP and adds some support to the theory the casein micelle CCP is made up of HAP.

Figure 7 shows the ${ }^{1} \mathrm{H}^{31} \mathrm{P}$ CP-MAS spectra and kinetics of casein micelle pellets chelated in a range of EDTA concentrations. From the CP spectra in Figure

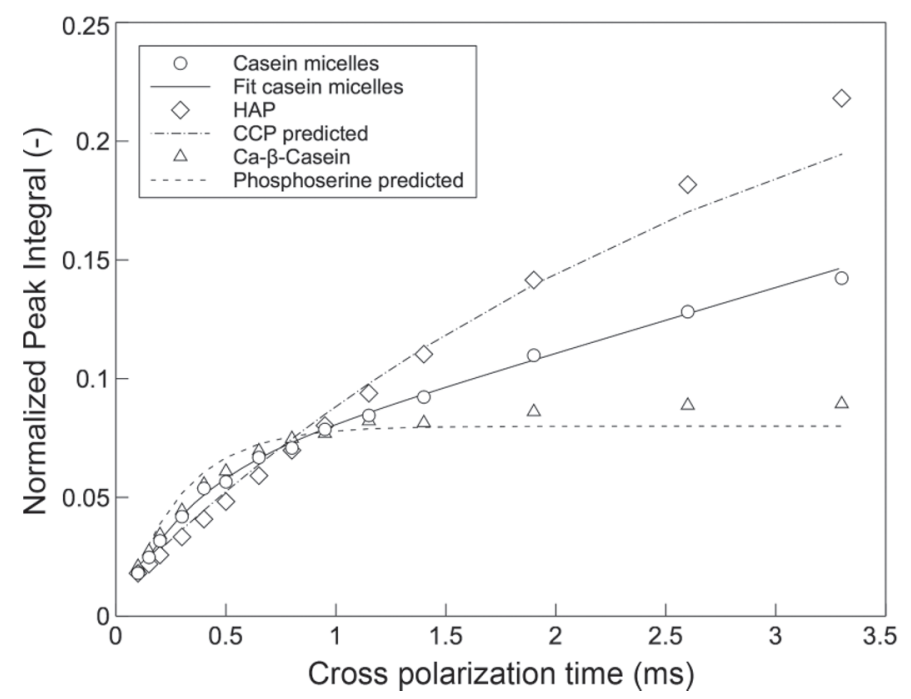

Figure 5. The ${ }^{1} \mathrm{H}_{-}{ }^{31} \mathrm{P}$ cross-polarization $(\mathrm{CP})$ kinetics of casein micelles, hydroxyapatite (HAP), and calcium- $\beta$-casein. The solid line is the fit to casein micelle CP kinetics with the 2 -species CP kinetic model in Eqn. [1] (produces $\tau_{\mathrm{CCP}}$ and $\tau_{\text {Pser }}$ ). The dashed and dashed-dotted lines are the predicted individual CP kinetics of the colloidal calcium phosphate (using $\tau_{\mathrm{CCP}}$ ) and phosphoserine (using $\tau_{\text {Pser }}$ ) extracted from casein micelle fit. Plots are normalized by the sum of point intensities. 
(a)

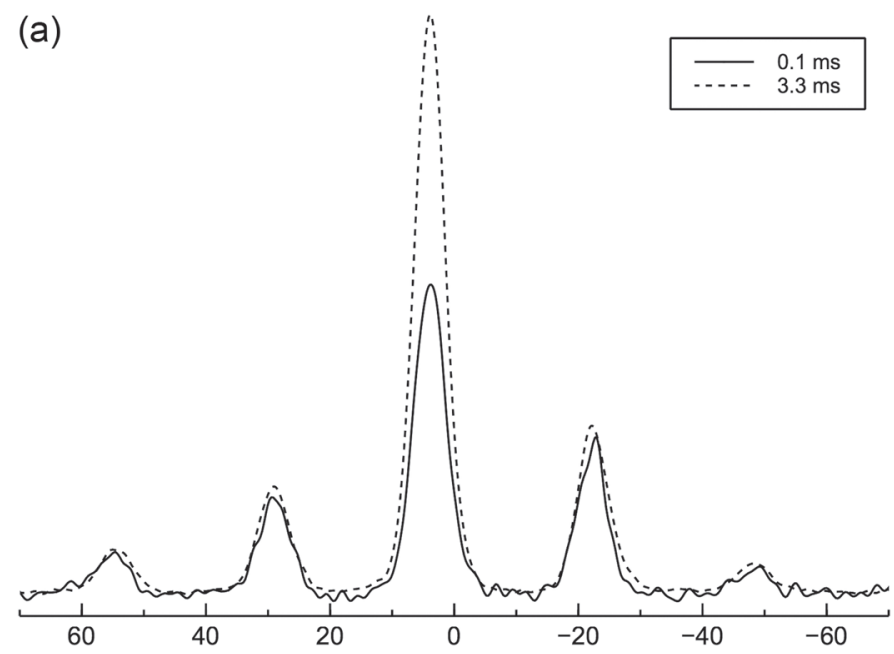

(b)

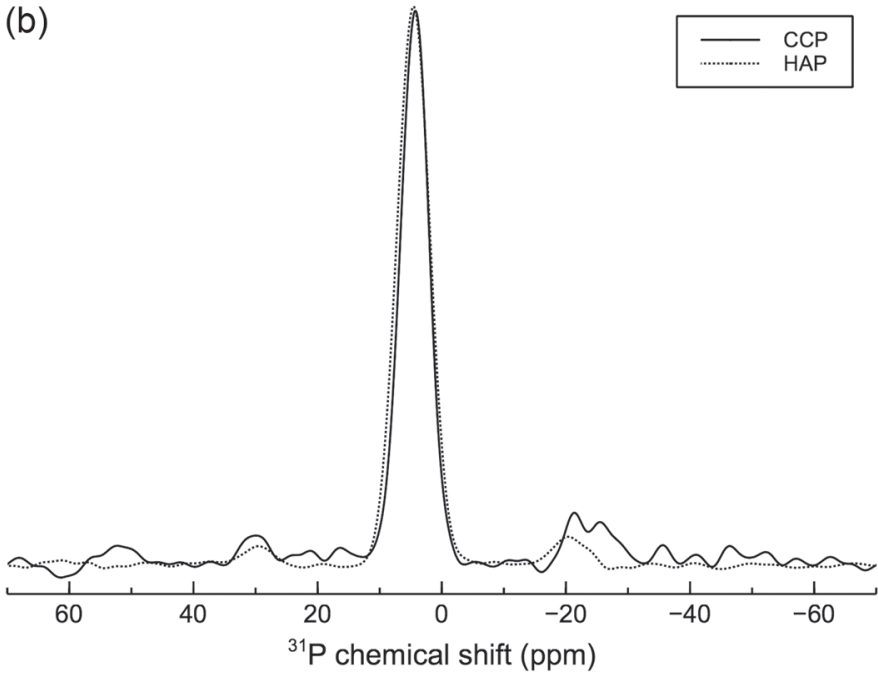

Figure 6. ${ }^{1} \mathrm{H}_{-}{ }^{31} \mathrm{P}$ Cross-polarization magic angle spinning $(\mathrm{CP}-$ MAS) spectra of (a) casein micelle pellets at cross-polarization times of 0.1 and $3.3 \mathrm{~ms}(0.1 \mathrm{~ms}$ spectra rescaled to predicted contribution of the overall spectra at $3.3 \mathrm{~ms}$ cross-polarization time); and (b) hydroxyapatite (HAP) and probable colloidal calcium phosphate (CCP) spectra. The CCP spectrum is the product of subtracting the 2 spectra in (a).

7a, it can be seen that the concentration of rigid phosphorus in the casein micelles was reduced with increasing EDTA concentration. The inserted plot in Figure $7 \mathrm{a}$ is the relative integral of the isotropic peak. The reduction in immobile phosphorus is directly proportional to the EDTA concentration. This is consistent with other studies of chelation of casein micelles with EDTA (Griffin et al., 1988; Mekmene and Gaucheron, 2011; Marchin et al., 2007). Colloidal calcium phosphate mobilization by EDTA produces similar changes in the CSA of the ${ }^{1} \mathrm{H}^{31} \mathrm{P}$ CP-MAS spectra in aging Mozzarella cheese (Figure 2), where the reduction in immobile phosphorus signal occurs predominantly in the isotropic peak and the spinning side-band peaks remain mainly unchanged.

By observing the CP kinetics, we can confirm which phosphorus species in the casein micelles (phosphoserine or CCP) is being mobilized by the EDTA. Figure $7 \mathrm{~b}$ shows the $\mathrm{CP}$ kinetics at each EDTA concentration. Below a CP time of $0.7 \mathrm{~ms}$, all curves are almost identical. Above $0.7 \mathrm{~ms}$, the slope of the curve decreases with increasing reduction in rigid phosphorus content of the casein micelles. Below a CP time of $0.7 \mathrm{~ms}$, the signal transfer is predominantly from the phosphoserine $\left(\tau_{P s e r}\right)$, as it has faster $\mathrm{CP}$ kinetics than the $\mathrm{CCP}\left(\tau_{\mathrm{CCP}}\right)$. Above

(a)

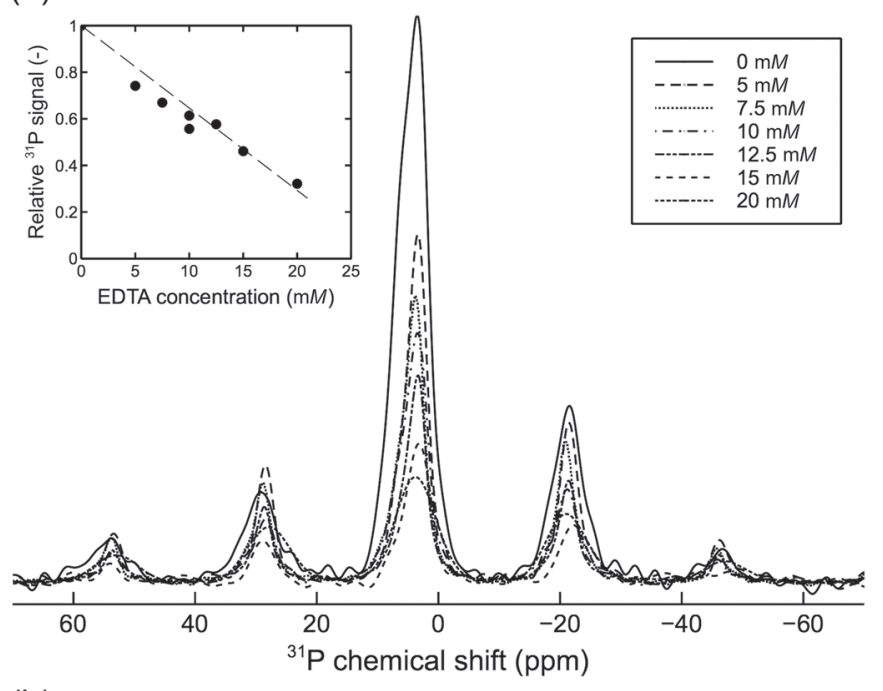

(b)

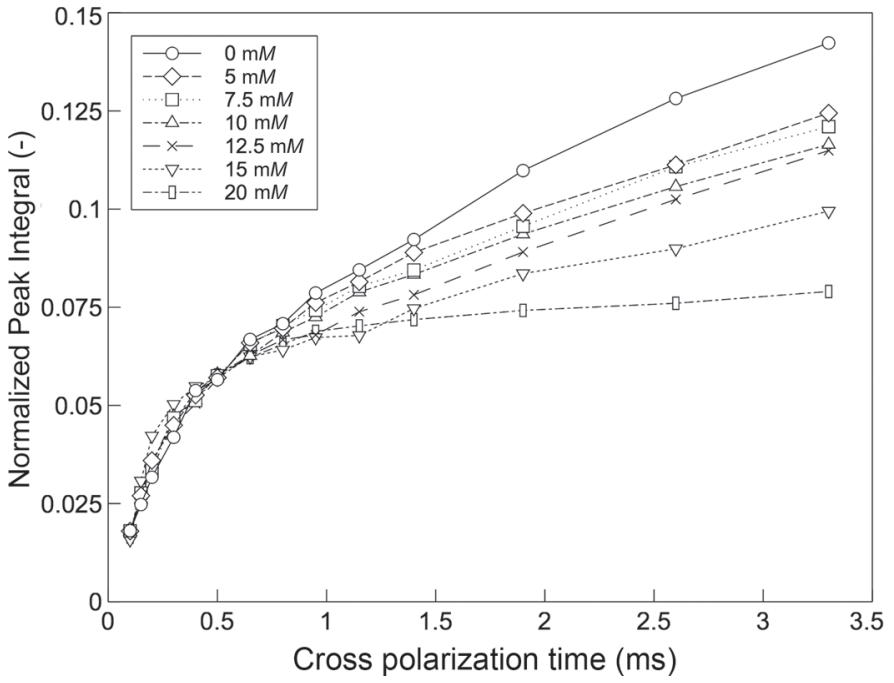

Figure 7. Casein micelle pellets chelated with various concentrations of EDTA: (a) ${ }^{1} \mathrm{H}^{31} \mathrm{P}$ cross-polarization magic angle spinning (CP-MAS) spectra (normalized by sample weight and insert figure is normalized by intensity at zero EDTA concentration), and (b) ${ }^{1} \mathrm{H}-{ }^{31} \mathrm{P}$ CP kinetics. 
$0.7 \mathrm{~ms}$, the phosphoserine transfer was nearly saturated so ${ }^{31} \mathrm{P}$ signal growth was only by transfer from the CCP. Curve fitting with Eqn. [1] implied that mobilization of rigid phosphorus was predominantly CCP. This agrees with observations of Udabage et al. (2000) with EDTA chelation of casein micelles. They determined that the binding constant of calcium bound to phosphoserine was greater than that of CCP. This results in a preferential mobilization of rigid phosphorus from the CCP with chelation of calcium by EDTA. As well, the ability to form a casein micelle pellet by ultracentrifugation at $50,000 \times g$ indicated that intact casein micelles remained in the $20 \mathrm{~m} M$ EDTA solution. The gravity was too low to settle free casein proteins. Transmission electron microscopy has also confirmed that casein micelles remain intact in $20 \mathrm{mM}$ EDTA (Marchin et al., 2007). With the CCP reduced to low levels, it is unlikely the rigid phosphorus remaining in casein micelles was only from the phosphoserine involved in calcium linkages with CCP. There is unlikely to be enough remaining $\mathrm{CCP}$ to form the observed amount rigid phosphoserine. Curve fitting the CP kinetics results suggested that $60 \%$ of the phosphoserine, but only $6 \%$ of the original $\mathrm{CCP}$, remained immobile in $20 \mathrm{~m} M$ EDTA. Therefore, the rigid phosphoserine remaining in the casein micelle must be the product of some other bonding structure in the casein micelles that holds the phosphoserine residues in an immobile state.

Figure 8 compares the ${ }^{1} \mathrm{H}-{ }^{31} \mathrm{P}$ CP-MAS spectra and kinetics of $20 \mathrm{~m} M$ EDTA-chelated casein micelles, calcium- $\beta-\mathrm{CN}$, and a mature cheese. The $\mathrm{CP}$ kinetics of the $20 \mathrm{~m} M$ EDTA and calcium- $\beta-\mathrm{CN}$ are almost the same. The calcium- $\beta-\mathrm{CN}$ is dry and contains no CCP so it only contains rigid phosphoserine residues complexed with calcium. This confirms that there was very little to no CCP present in the $20 \mathrm{~m} M$ EDTA casein micelles. The 40-d-old Mozzarella cheese CP kinetics differed above a $\mathrm{CP}$ time of $0.7 \mathrm{~ms}$ (Figure 8a), indicating that some CCP remained. Fitting with Eqn. [1] estimated the CCP content of the 40-d-old Mozzarella cheese to be $15 \%$ of the native casein micelle levels. Although the CCP is present in the 40-d-old Mozzarella, the rigid phosphorus content appears to be predominantly phosphoserine. The CP-MAS spectra CSA patterns of the $20 \mathrm{~m} M$ EDTA and mature cheeses were very similar. The main difference was that the intensity of the isotropic peak was higher in the mature cheeses. This was expected, as the CP kinetic curves showed higher levels of CCP remaining in the mature cheese.

When comparing the spectra of the $20 \mathrm{~m} M$ EDTA and mature cheese samples to the calcium- $\beta-\mathrm{CN}, 2$ distinctive differences were observed; the right first-order spinning side band had a higher intensity and all peaks were broader for the calcium- $\beta-\mathrm{CN}$. The higher right first-order peak was likely due to a greater concentration of phosphoserine residues in the calcium- $\beta-\mathrm{CN}$ being complexed with calcium. Figure 3 shows that the slope of the first-order peaks was directly proportional to the concentration of calcium complexing to the phosphate site. The broadening of peaks is generally caused by proton-to-phosphorus coupling; the greater the proton coupling, the broader the peaks. However, the $\mathrm{CP}$ measurements shown in Figure 8 indicate little to no difference in proton-to-phosphorus coupling for the 3 samples. The narrower peaks could be due to the ${ }^{31} \mathrm{P}$ site in the phosphoserine having a smaller distribution of angles relative to the applied magnetic field. It is known in solid-state NMR that increased molecular
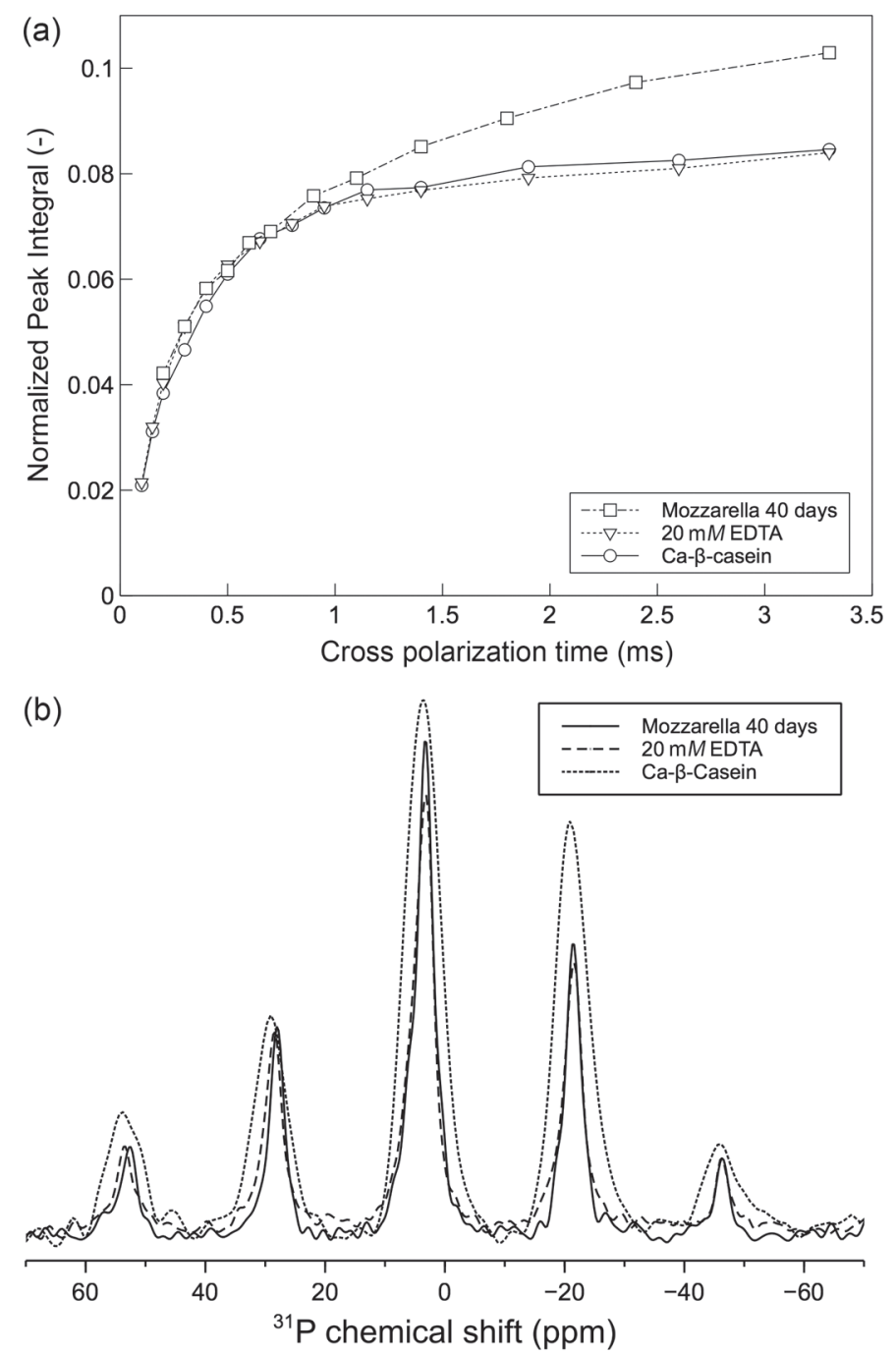

Figure 8. Calcium- $\beta$-casein, $20 \mathrm{~m} M$ EDTA-chelated casein micelles, and mature cheese: (a) ${ }^{1} \mathrm{H}_{-}{ }^{31} \mathrm{P}$ cross-polarization (CP) kinetics; and (b) ${ }^{1} \mathrm{H}-{ }^{31} \mathrm{P}$ spectra (normalized by the total spectral signal). 
ordering of bond angles of a population of nuclei will produce narrower peaks in solid-state NMR spectra (Bak et al., 2001; Harris et al., 2012). This suggests the rigid phosphoserine residues in the $20 \mathrm{~m} M$ EDTA and 40-d-old Mozzarella samples have a bonding structure that aligns them in a narrow range of molecular orientations.

To summarize the determined characteristics of the rigid phosphorus remaining in 40-d-old Mozzarella cheese and $20 \mathrm{mM}$ EDTA chelated casein micelles, (1) they are predominantly rigid phosphoserine residues and not CCP; (2) they are not the product of phosphoserine to CCP bridging due to low levels of CCP remaining; (3) phosphates complexed to calcium; (4) the rigidity is highly localized to the phosphoserine phosphate site; (5) the rigidity and bond coupling is relatively unaffected by hydration; and (6) the rigid phosphorus nuclei share a narrow range of molecular orientations.

From these characteristics, it is clear that a bonding structure other than calcium phosphoserine to CCP bridging is present in the casein micelle, as illustrated in Figure 1. The most likely candidates are calciumbridged phosphoserine-to-phosphoserine linkages, being either intra- or inter-protein. Also, the phosphoserineto-phosphoserine linkages may incorporate a small number of phosphate ions. Figure 9 illustrates some of the possible structures of these previously unidentified linkages. The calcium bridge at the phosphoserine phosphate site is important because without it the phosphate group would not have the rigidity for $\mathrm{CP}$ to occur. The presence of the calcium ion alone does not produce rigidity in the phosphoserine phosphate site, as seen in the lack of rigid phosphorus in hydrated calcium- $\beta-C N$. Several researchers have postulated the existence of these cross-linkages in casein micelles. Velev et al. (1998) observed, with $\beta$-CN-stabilized emulsions, that the film layer thickness collapsed when the calcium concentration reached or exceeded $10 \mathrm{~m} M$. They suggested that the collapse was due to calcium ions forming cross-links between phosphoserine residues of the casein proteins. Zhang and Aoki (1996) concluded, from NMR measurements of ${ }^{45} \mathrm{Ca}$ - and ${ }^{32} \mathrm{P}$-exchanged casein micelles, that calcium in casein micelles could be divided into the 3 types: (1) exchanged and not reexchanged; (2) exchanged and re-exchanged; and (3) hard to exchange. The hard-to-exchange calcium was involved in a bonding structure that was more stable than those involved in the bridging of the CCP. Mekmene and Gaucheron (2011) supported this finding by measuring the calcium association constants of $\beta-\mathrm{CN}$ and $\mathrm{CCP}$, finding $\beta-\mathrm{CN}$ to have an association constant 5 times greater than CCP. Famelart et al. (2009) studied the acid gelation of calcium phosphate-depleted preheated milk by chelation and found that the rheological properties of the acid gel depended more on the initial phosphoserine-bound calcium than on the total initial CCP content of the casein micelles. They interpreted this as indicating that another calciumphosphate bonding structure was present in the casein micelles other than the CCP linkages that governed the structural properties of the micelle. Muir and Glimcher (1984) studied the calcification of bone and suggested that phosphorylated sites on the same collagen fibril were intra-bridged with calcium similarly to that shown in Figure 9c. These intra-linked phosphorylated sites provided rigid charged zones that act as nucleation sites for calcium phosphate. Muir and Glimcher (1984) postulated that the rigid phosphoserine linkages inhibit calcium phosphate crystallization by altering the bonding angle between calcium and phosphate ions. It is possible that the calcium-bridged phosphoserineto-phosphoserine linkages in casein micelles provide a similar function during the formation of the casein
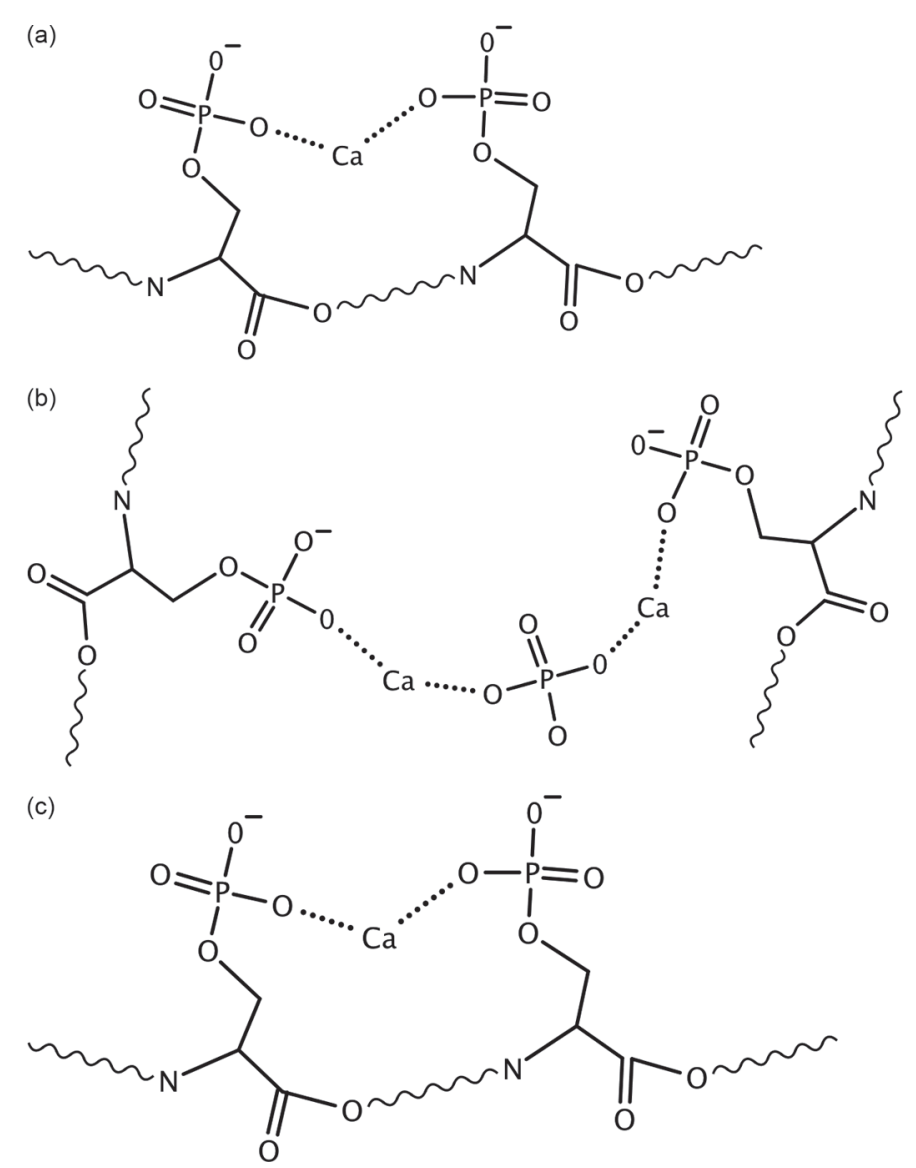

Figure 9. Schema of proposed bonding structures of calciumbridged phosphoserine to phosphoserine linkages in casein micelles: (a) inter-protein linkages, (b) inter-protein incorporating a phosphate ion, and (c) intra-protein linkages. 
micelle. The linkages are formed in the initial casein micelle assemblage to provide heterogeneous nucleation sites for calcium phosphates to precipitate on to but not crystallize. However, because of their rigidity, they are able to constrain the bonding angles of the calcium phosphates so as they do not form crystalline calcium phosphate and are retained in an amorphous state. This would provide the casein micelles with their innate ability to transport calcium phosphates in far greater concentrations than that of the saturated solution concentration they are in (Wahlgren et al., 2009).

\section{CONCLUSIONS}

By using ${ }^{1} \mathrm{H}_{-}{ }^{31} \mathrm{P}$ CP-MAS spectra and $\mathrm{CP}$ kinetics measurements of casein micelles and reference components ( $\beta$-casein and HAP), we have identified immobile phosphorus bodies observed in aged Mozzarella cheese and $20 \mathrm{mM}$ EDTA-chelated casein micelles. The phosphorus bodies were characterized as follows: they are immobile phosphoserine residues (not CCP), they are not the product of phosphoserine to CCP bridging, the phosphate is complexed to calcium, their rigidity is highly localized to the phosphorus site, their rigidity and bond coupling is relatively unaffected by hydration, and they share a narrow range of molecular orientations. Combining these observed properties, the most likely explanation is a calcium-to-phosphorus bonding structure in the casein micelle that has not been previously classified in the scientific literature or are possibly unidentified as follows. The most likely candidates are calcium-bridged phosphoserine-to-phosphoserine linkages (intra- or inter-protein) in casein micelles.

\section{ACKNOWLEDGMENTS}

The authors acknowledge the financial support of Fonterra Research and Development Centre (Palmerston North, New Zealand) and the New Zealand Ministry for Primary Industries via the Primary Growth Partnership, Transforming the Dairy Value Chain. We acknowledge access to equipment and laboratories at the Institute of Fundamental Sciences, Massey University (Palmerston North, New Zealand). We thank Jeremy Smith (Food Technology, Massey University) for the use of his cheese samples.

\section{REFERENCES}

Bak, M., L. K. Rasmussen, T. E. Petersen, and N. C. Nielsen. 2001. Colloidal calcium phosphates in casein micelles studied by slowspeed-spinning ${ }^{31} \mathrm{P}$ magic angle spinning solid-state nuclear magnetic resonance. J. Dairy Sci. 84:1310-1319. https://doi. org/10.3168/jds.S0022-0302(01)70160-9.
Bingham, E. W. 1979. Role of mammary casein kinase in the phosphorylation of milk proteins. J. Dairy Res. 46:181-185. https:// doi.org/10.1017/S0022029900017015.

Dalgleish, D. G. 2011. On the structural models of bovine casein micelles-Review and possible improvements. Soft Matter 7:22652272. https://doi.org/10.1039/C0SM00806K.

Famelart, M.-H., G. Gauvin, D. Pâquet, and G. Brule. 2009. Acid gelation of colloidal calcium phosphate-depleted preheated milk. Dairy Sci. Technol. 89:335-348. https://doi.org/10.1051/dst/2009014.

Gaucheron, F. 2005. The minerals of milk. Reprod. Nutr. Dev. 45:473483. https://doi.org/10.1051/rnd:2005030.

Gobet, M., C. Rondeau-Mouro, S. Buchin, J.-L. Le Quéré, E. Guichard, L. Foucat, and C. Moreau. 2010. Distribution and mobility of phosphates and sodium ions in cheese by solid-state ${ }^{31} \mathrm{P}$ and double-quantum filtered ${ }^{23} \mathrm{Na}$ NMR spectroscopy. Magn. Reson. Chem. 48:297-303. https://doi.org/10.1002/mrc.2576.

Griffin, M. C., R. L. Lyster, and J. C. Price. 1988. The disaggregation of calcium-depleted casein micelles. Eur. J. Biochem. 174:339-343.

Guinee, T. P., and B. T. O'Kennedy. 2009. The effect of calcium content of Cheddar-style cheese on the biochemical and rheological properties of processed cheese. Dairy Sci. Technol. 89:317-333. https://doi.org/10.1051/dst/2009009.

Harris, R. K., R. E. Wasylishen, and M. J. Duer. 2012. NMR Crystallography. John Wiley \& Sons, Chichester, UK.

Hassan, A., M. E. Johnson, and J. A. Lucey. 2004. Changes in the proportions of soluble and insoluble calcium during the ripening of Cheddar cheese. J. Dairy Sci. 87:854-862. https://doi.org/10.3168/ jds.S0022-0302(04)73229-4.

Holt, C. 2004. An equilibrium thermodynamic model of the sequestration of calcium phosphate by casein micelles and its application to the calculation of the partition of salts in milk. Eur. Biophys. J. 33: https://doi.org/10.1007/s00249-003-0377-9.

Holt, C., M. J. J. M. van Kemenade, L. S. Nelson, L. Sawyer, J. E. Harries, R. T. Bailey, and D. W. L. Hukins. 1989. Composition and structure of micellar calcium phosphate. J. Dairy Res. 56:411416. https://doi.org/10.1017/S0022029900028880.

Horne, D. S. 1998. Casein interactions: Casting light on the black boxes, the structure in dairy products. Int. Dairy J. 8:171-177.

Horne, D. S. 2011. Milk proteins | Casein, micellar structure. Pages 772-779 in Encyclopedia of Dairy Sciences. J. W. Fuquay, ed. Elsevier, Philadelphia, PA.

Kelly, P. M., J. Kelly, R. Mehra, D. J. Oldfield, E. Raggett, and B. T. O'Kennedy. 2000. Implementation of integrated membrane processes for pilot scale development of fractionated milk components. Lait 80:139-153. https://doi.org/10.1051/lait:2000101.

Kolodziejski, W., and J. Klinowski. 2002. Kinetics of cross-polarization in solid-state NMR: A guide for chemists. Chem. Rev. 102:613628. https://doi.org/10.1021/cr000060n.

Lucey, J. A., and P. F. Fox. 1993. Importance of calcium and phosphate in cheese manufacture-A Review. J. Dairy Sci. 76:1714-1724.

Marchin, S., J.-L. Putaux, F. Pignon, and J. Léonil. 2007. Effects of the environmental factors on the casein micelle structure studied by cryo transmission electron microscopy and small-angle $\mathrm{x}$ ray scattering/ultrasmall-angle x-ray scattering. J. Chem. Phys. 126:045101 https://doi.org/10.1063/1.2409933.

Mekmene, O., and F. Gaucheron. 2011. Determination of calciumbinding constants of caseins, phosphoserine, citrate and pyrophosphate: A modelling approach using free calcium measurement. Food Chem. 127:676-682. https://doi.org/10.1016/j. foodchem.2010.12.121.

Muir, H., and M. J. Glimcher. 1984. Recent studies of the mineral phase in bone and its possible linkage to the organic matrix by protein-bound phosphate bonds. Philos. Trans. R. Soc. Lond. B 304:508. (Discussion)

Phadungath, C. 2005. Casein micelle structure: A concise review. Songklanakarin Journal of Science and Technology 27:199-212.

Rasmussen, L. K., E. S. Sørensen, T. E. Petersen, N. C. Nielsen, and J. K. Thomsen. 1997. Characterization of phosphate sites in native ovine, caprine, and bovine casein micelles and their caseinomacropeptides: A solid-state phosphorus-31 nuclear magnetic resonance 
and sequence and mass spectrometric study. J. Dairy Sci. 80:607614. https://doi.org/10.3168/jds.S0022-0302(97)75977-0.

Sleigh, R. W., A. G. Mackinlay, and J. M. Pope. 1983. NMR studies of the phosphoserine regions of bovine $\alpha_{\mathrm{S} 1}$-and $\beta$-casein: Assignment of 31P resonances to specific phosphoserines and cation binding studied by measurement of enhancement of $1 \mathrm{H}$ relaxation rate. Biochim. Biophys. Acta Protein Struct. Mol. Enzymol. 742:175183

Thomsen, J. K., H. J. Jakobsen, N. C. Nielsen, T. E. Petersen, and L. K. Rasmussen. 1995. Solid-state magic-angle spinning ${ }^{31} \mathrm{P}-\mathrm{NMR}$ studies of native casein micelles. Eur. J. Biochem. 230:454-459. https://doi.org/10.1111/j.1432-1033.1995.0454h.x.

Udabage, P., I. R. Mckinnon, and M.-A. Augustin. 2000. Mineral and casein equilibria in milk: Effects of added salts and calcium-chelating agents. J. Dairy Res. 67:361-370. https://doi.org/10.1017/ S0022029900004271.

Velev, O. D., B. E. Campbell, and R. P. Borwankar. 1998. Effect of calcium ions and environmental conditions on the properties of $\beta$-casein stabilized films and emulsions. Langmuir 14:4122-4130. https://doi.org/10.1021/la980212y.

Wahlgren, N. M., P. Dejmek, and T. Drakenberg. 2009. A ${ }^{43} \mathrm{Ca}$ and ${ }^{31} \mathrm{P}$ NMR study of the calcium and phosphate equilibria in heated milk solutions. J. Dairy Res. 57:355-364. https://doi.org/10.1017/ S0022029900027011.

Wu, Y., J. L. Ackerman, E. S. Strawich, C. Rey, H. M. Kim, and M. J. Glimcher. 2003. Phosphate ions in bone: Identification of a calcium-organic phosphate complex by ${ }^{31} \mathrm{P}$ solid-state NMR spectroscopy at early stages of mineralization. Calcif. Tissue Int. 72:610-626. https://doi.org/10.1007/s00223-002-1068-8.

Wu, Y., M. J. Glimcher, C. Rey, and J. L. Ackerman. 1994. A unique protonated phosphate group in bone mineral not present in synthetic calcium phosphates: Identification by phosphorus-31 solidstate NMR spectroscopy. J. Mol. Biol. 244:423-435.

Zhang, Z. P., and T. Aoki. 1996. Behaviour of calcium and phosphate in bovine casein micelles. Int. Dairy J. 6:769-780. https://doi org/10.1016/0958-6946(96)00006-4. 